Spyridon Oikonomidis \& Costas A. Thanos

\title{
Germination of Anacamptis sancta (Orchidaceae) in nutrient media, water agar and various light regimes
}

\begin{abstract}
Oikonomidis, S. \& Thanos, C. A.: Germination of Anacamptis sancta (Orchidaceae) in nutrient media, water agar and various light regime. [In Magrini, S. \& Salmeri, C. (eds), Mediterranean plant germination reports - 3]. Fl. Medit. 31: 271-276. 2021. http://dx.doi.org/10.7320/FlMedit31.271

The asymbiotic seed germination of orchids is a complex process with considerable technical difficulties, due to the natural requirement of a plant-fungus symbiotic relationship under field conditions. Only on rare occasions, orchid seeds are known to germinate readily in water. Anacamptis sancta is a relatively common orchid species with its main distribution around the East Mediterranean Sea (Greece, Cyprus, Turkey, Lebanon, Syria and Israel). Germination of $A$. sancta seeds was tested in different nutrient media, water agar and under various light regimes, in asymbiotic culture. In most experimental conditions tested, high germination percentages were observed with the highest germination $(85.5 \%)$ obtained with a modified version of Malmgren medium without coconut water, under white light (12/12 h) at $20^{\circ} \mathrm{C}$. In this study, results from all the experiments carried out are presented.
\end{abstract}

Key words: asymbiotic germination, Greece, holy orchid, phytochrome.

\section{Introduction}

Orchid seeds are among the smallest-sized ones. They consist of a spindle-shaped, thin seed coat that encloses the underdeveloped embryo. Due to the rudimentary structure of the orchid embryo, comprised of just a cluster of undifferentiated cells, there are no wellshaped embryonic organs, in most cases, and thus germination cannot be defined by the concept of radicle emergence from the seed coat. A system of developmental stage evaluation has been put forward for the assessment of orchid seed germination (Zettler \& Hofer 1998) and it is commonly used in most relevant studies. Therefore, in this work, according to Zettler \& Hofer (1998), germination is considered to take place as soon as the rhizoids have started to develop.

Anacamptis sancta (L.) R.M. Bateman, Pridgeon \& M.W. Chase, commonly known as the holy orchid, is a relatively common species with its main distribution around the East Mediterranean Sea (Greece, Cyprus, Turkey, Lebanon, Syria and Israel). In Greece, it is found growing in numerous small populations, mostly in Mediterranean grasslands and phrygana, from sea level up to $500 \mathrm{~m}$. It is a species that is commonly collected for salep production and in some cases, especially in Turkey, its populations are threatened due to overcollection (Bozdemir \& al. 2018). 
A. sancta is one of the eleven taxa of the genus Anacamptis, native in Greece. While the rest of the members of the genus are deceptive species regarding pollination, A. sancta and its closely related A. coriophora (L.) R.M. Bateman, Pridgeon \& M.W. Chase are rewarding ones (Claessens \& Kleynen 2011).

Regarding seed germination data, the Anacamptis genus is regarded as one of the easier to germinate Mediterranean orchid genera (Rasmussen 1995; Magrini \& al. 2011; Dulic \& al. 2020). Most of the Anacamptis taxa, occurring in Greece, tested so far exhibit final germination percentages over $60 \%$ and in most cases full germination is achieved $(>80-90 \%)$ with the only exception of $A$. collina (Banks \& Sol. ex Russell) R.M. Bateman, Pridgeon $\&$ M.W. Chase the germination of which did not exceed 15\% (unpublished data of our lab). A. sancta is a relatively easily germinating species, known from previous studies by Bozdemir \& al. (2018) and Pritchard (1989) with germination levels of 74 and 84\%, respectively; in these studies, germination was tested in continuous darkness while the media with the highest germination percentages were a modified version of Waes \& Debergh with the addition of $40 \mathrm{~g} / \mathrm{L}$ sucrose and Norstog medium, respectively.

In the present work, we investigated the asymbiotic germination of $A$. sancta seeds, collected from a population in Paros Island (Cyclades Islands, Aegean Sea), with various nutrient media and water agar, under various light regimes, at two different temperatures; it is noteworthy that the germinability both in water and under various light conditions are tested for the first time.

49. Anacamptis sancta (L.) R.M. Bateman, Pridgeon \& M.W. Chase (Orchidaceae)

\section{Accession data}

Gr: Greece, loc. Paros Island (Cyclades Islands) (WGS84: $\left.37.0820^{\circ} \mathrm{N}, 25.1634^{\circ} \mathrm{E}\right), 314$ m a.s.1., 15 Jun 2019, K. Zafiriou (NKUA/GR-Acc. OR003, Seed Bank of National and Kapodistrian University of Athens).

\section{Germination data}

Pre-treatments: Disinfection with $5 \% \mathrm{Ca}(\mathrm{OCl})_{2}+1 \%$ Tween 80 solution for 15 min followed by three rinses in sterilized distilled water.

Germination media: Mm) modified (type 1) Malmgren medium (Malmgren 1996, modified by Kitsaki \& al. 2004): $75 \mathrm{mg} / \mathrm{L}(\mathrm{Ca})_{3} \mathrm{PO}_{4}, 75 \mathrm{mg} / \mathrm{L} \mathrm{KH}_{2} \mathrm{PO}_{4}, 75 \mathrm{mg} / \mathrm{L} \mathrm{MgSO}{ }_{4}\left(\mathrm{H}_{2} \mathrm{O}\right)_{7}$, $10 \mathrm{mg} / \mathrm{L}$ sucrose, $50 \mathrm{~mL} / \mathrm{L}$ coconut water, $6 \mathrm{~g} / \mathrm{L}$ agar and $0.5 \mathrm{~g} / \mathrm{L}$ charcoal, at $\mathrm{pH} 5.8 ; \mathrm{M} 1)$ modified (type 2): Mm without coconut water.

Sample size: ca. 250 seeds for each test $(50 \times 5$ replicates $)$.

\begin{tabular}{|c|c|c|c|c|c|c|}
\hline Germination & Thermoperiod & $\begin{array}{l}\text { Photoperiod } \\
\text { [light/dark] }\end{array}$ & $\mathbf{T}_{1}[\mathbf{d}]$ & $\mathbf{T}_{50}[\mathrm{~d}]$ & $\mathbf{T}_{\max }[\mathbf{d}]$ & $\begin{array}{c}\text { MTG } \\
\text { [d] }\end{array}$ \\
\hline $85.5 \%^{1}$ & constant $20^{\circ} \mathrm{C}$ & $12 / 12 \mathrm{~h}$ & 7.0 & 4.2 & 20.0 & 8.0 \\
\hline $83.1 \%^{2}$ & constant $20^{\circ} \mathrm{C}$ & $0 / 24 h$ & - & - & - & - \\
\hline
\end{tabular}




\section{Observations}

Mature seed pods were collected in June 2019 from a wild population (56 mature individuals) of $A$. sancta in Paros Island. A total of 76 seed pods from 35 individuals (2-3 per plant) were collected and they were taken to the Seed Bank of the National and Kapodistrian University of Athens where seeds were extracted and placed in glass vials, at $4{ }^{\circ} \mathrm{C}$, until the end of the experiments (Fig. 1).

It should be noted that the seed lot viability, as assessed via a TTZ + Trypan blue test (Magrini \& al. 2019), was found to be relatively low (60.9 $\pm 9.5 \%)$.

For the experiments, we tested another pre-treatment, cold stratification for 20 days at $5^{\circ} \mathrm{C}$, and other four germination media: modified (type 3) Malmgren (M2): Mm with the addition of $0.2 \mathrm{~g} / \mathrm{L} \mathrm{NH}_{4} \mathrm{NO}_{3}$; modified (type 4) Malmgren (M3): Mm with the addition of $1 \mathrm{~g} / \mathrm{L}$ casein tryptic peptone; modified (type 5) Malmgren (M4): Mm with the addition of $0.2 \mathrm{~g} / \mathrm{L} \mathrm{NH}_{4} \mathrm{NO}_{3}$ and $1 \mathrm{~g} / \mathrm{L}$ casein tryptic peptone; (WA) $2 \%$ agar.

The dishes were incubated at 15 and $20^{\circ} \mathrm{C}$ under several light regimes: i) continuous darkness $(\mathrm{CD})$, the seeds remained in the dark until the end of the experiment, germination was counted only once at the end; ii) $12 / 12 \mathrm{~h}$ white light/darkness (L/D-2) with $\mathrm{z}=1.44$. The $\mathrm{z}$, the ratio of the wavelengths $660 \mathrm{~nm}$ and $730 \mathrm{~nm}$, was calculated with a Skye red/far red sensor); iii) total darkness (TD), seed imbibitions took place under green safelight and thereafter as in CD; iv) 12/12 h white light/darkness (L/D-1) with $\mathrm{z}=7.93$; v) 12/12 h white light/darkness (L/D-2) with $\mathrm{z}=1.44$; vi) $5 / 55 \mathrm{~min}$ red light/darkness $(\mathrm{R})$; vii) $5 / 55 \mathrm{~min}$ farred light/darkness (FR); viii) continuous red light (CR); ix) continuous far-red light (CFR); $\mathrm{x}$ ) continuous white light, $\mathrm{z}=1.44(\mathrm{CWL})$; $\mathrm{xi}$ ) continuous blue light (CBL); xii) 5/5/50 min far-red light/red light/darkness (FR/R/D); xiii) 5/5/50 min red light/far-red light/darkness (R/FR/D); xiv) Darkness (D), the seeds remained in the dark with short exposures $(\sim 1-2$

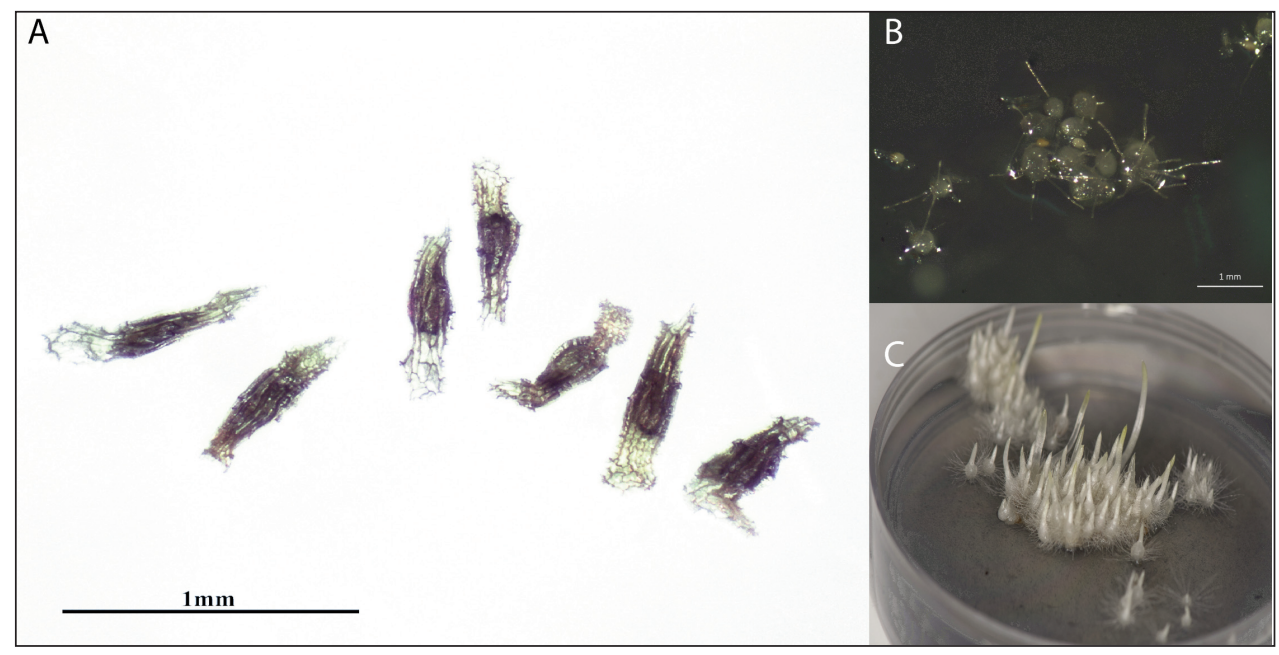

Fig. 1. A. sancta. A: dry seeds; B: germinated seeds in modified (type 2) Malmgren (Mm), at the developing rhizoids stage; C: germinated seed in modified (type 2) Malmgren (Mm) at the protocorm plus initial shoot stage (scale bar: $1 \mathrm{~mm}$ ). 
min) to stereomicroscope light during the germination counts. Except for TD, where the sowing took place in a dark chamber under a green safelight, for the rest of the experiments the seeds were sown under the light of the laminair (to avoid fungal or bacterial infections).

A. sancta is an apparently 'easy' species to germinate (Pritchard 1989; Bozdemir \& al. 2018). In our study, optimal germination results were reached in most of the treatments used, and in some cases higher than previously reported (Pritchard 1989; Bozdemir \& al. $2018 ; 74 \%$ and $84 \%$, respectively), taking also into account the rather low viability of the seed lot. The highest final germination of seeds pretreated with $5 \% \mathrm{Ca}(\mathrm{OCl})_{2}+1 \%$ Tween 80 for $15 \mathrm{~min}(85.5 \%)$ was achieved in M1 medium and under L/D (12/12, $\mathrm{z}=7.93)$, while the lowest germination (53.7\%) was observed in Mm medium after 20 days of chilling $\left(5^{\circ} \mathrm{C}\right)$, in darkness. From the six media tested, M1 gave the highest results while M2 gave the lowest ones $\left(64.9 \%\right.$ at $20^{\circ} \mathrm{C}$ under $\left.\mathrm{L} / \mathrm{D}-12 / 12, \mathrm{z}=1.44\right)$, while $\mathrm{M} 3$ and M4 media both yielded similar final germination (75-77\%) both in darkness and in L/D (12/12).

In addition, it is the first time that the germination of $A$. sancta is observed in water agar. Almost optimal germination $(72.9 \%)$ was achieved at $20^{\circ} \mathrm{C}$ when seeds were imbibed on $2 \%$ agar (no nutrients added). Regarding temperature, both 20 and $15^{\circ} \mathrm{C}$ resulted in high germination $(>70 \%)$ with only slight differences between them.

Despite the well-known fact that germination of small seeds is usually promoted by light, an increasing number of orchids have been reported to have seeds with photoinhibited germination (Rasmussen 1995; Carta \& al. 2017). A. sancta is an exception to this group of orchids; seed germination of $A$. sancta is over $50 \%$ under every light regime used in this study. For $\mathrm{Mm}$, which is the medium used in each different light regime test, the highest germination percentage was obtained in continuous darkness although the difference $(\sim 4 \%)$ with continuous white light $(\mathrm{z}=1.44)$ is not significant. Regarding the light regime, the lowest final germination observed was under continuous blue light (58.2\%) which may imply a negative effect of blue light in the germination of $A$. sancta seeds, while both R and FR light did not affect significantly the high germination levels. Therefore, under the conditions tested, we cannot detect any phytochrome control on seed germination of A. sancta. Most terrestrial orchid germination is tested in darkness (Rasmussen 1995) but further experimentation with light conditions might reveal a number of species whose seeds are indifferent to (or even promoted by) light.

\section{Conclusion}

Orchid minuscule seeds with their underdeveloped embryos lack sufficient nutrients to support germination and early seedling development. In most cases, in nature, a mycosymbiont provides nutrients (Bernard 1899, 1909) to the seedling in the first stages of its development, while in the laboratory, nutrients are provided by the culture media used (Knudson 1921, 1922). Relatively few species of the family Orchidaceae can readily germinate in water and the final germination level is usually low (Rasmussen 1995). In this study, we present a successful protocol for germination of $A$. sancta which yielded higher final germination than previously reported in nutrient media. We also demonstrate, for the first time, the ability of the species to readily germinate in water agar without any nutrients added, as recently reported also for Neotinea maculata (Desf.) Stearn (Oikonomidis \& al. 2020). However, seeds sown in nutrient media reached a stage 4-5 in the Zettler \& Hofer scale (Zettler \& Hofer 1998), while seeds imbibed in water agar reached 3-4. Moreover, we additionally report the 'insensitive nature' of seed germination towards light or darkness. 
The temperatures tested $\left(15\right.$ and $\left.20^{\circ} \mathrm{C}\right)$ did not show any significant difference in the final germination results during the initial experiments and henceforth we used $20^{\circ} \mathrm{C}$, as this temperature is most common for orchids (Rasmussen 1995). The highest germination (85.5\%) was observed in the M1 medium. A. sancta is one of the few orchid species known (Rasmussen 1995) to readily germinate in water with almost full germination, while it is one, if not the only, species reported to reach the protocorm stage in water agar.

Species that readily germinate in water like $A$. sancta can be utilized as means for further understanding the germination physiology of species that exhibit hindered germination either in common orchids (e.g. in the genus Neotinea, Oikonomidis \& al. 2020) or in rare and endangered ones (e.g. in the genus Dactylorhiza where germination in water was also observed in several species, Rasmussen 1995).

The germination of $A$. sancta starts roughly at $24 \mathrm{~h}$ from the onset of imbibition while final germination is reached two weeks after, and protocorms are ready for the first nutrient medium transfer (repotting) one month after the seed sowing. This make A. sancta one of the fastest germinating terrestrial orchid species. Taking into additional consideration the high demand for orchid tubers, collected in the wild in the Eastern Mediterranean for salep powder, A. sancta may prove a good candidate for further studying germination and development of protocorms for field or greenhouse cultivation. This would provide leverage against overcollection from wild populations and enhance in situ conservation of the species.

\section{Acknowledgements}

The authors want to thank Associate Professors Kosmas Charalambidis and Andreas Roussis for providing the laminair for seed sowing. Also, we thank Katerina Zafiriou for collecting the plant material from Paros Island for the Seed Bank of National and Kapodistrian University of Athens.

\section{References}

Bernard N. 1899: Sur la germination du Neottia nidus-avis. - C. R. Hebd. Sceances Acad. Sci. 128: 1253-1255.

— 1909: L'evolution dans la symbiose, les orchidées et leurs champignons commensaux. - Ann. Sci. Nat. 9: 1-196.

Bozdemir, H., Cig, A. \& Turkoglu, N. 2018: Effects of different concentrations of carbohydrate forms on Orchis sancta L. propagation in vitro. - Appl. Ecol. Environm. Res. 16: 4849-4864. https://doi.org/10.15666/aeer/1604_48494864

Carta, A., Skourti, E., Mattana, E., Vandelook, F. \& Thanos, C. A. 2017: Photoinhibition of seed germination: Occurrence, ecology and phylogeny. - Seed Sci. Res. 27: 131-153. https://doi.org/10.1017/S0960258517000137

Claessens, J. \& Kleynen, J. 2011: The flower of the European orchid: Form and function. Voerendaal, Stein.

Dulic, J., Ljubojevic, M., Savic, D., Ognjanov, V., Dulic, T., Barac, G. \& Milovic, M. 2020: Implementation of SWOT analysis to evaluate conservation necessity and utilization of natural wealth: Terrestrial orchids as a case study. - J. Environ. Plan. Manag. 63(12): 2265-2286. https://doi.org/10.1080/09640568.2020.1717935

Kitsaki, C. K., Zygouraki, S., Ziobora, M., Kintzios, S. 2004: In vitro germination, protocorm formation and plantlet development of mature versus immature seeds from several Ophrys species (Orchidaceae). - Pl. Cell. Rep. 23: 284-290. https://doi.org/10.1007/s00299-004-0841-8 
Knudson, L. 1921. La germinacion no simbiotica de las semillas de orquideas. - Bull. R. Soc. Esp. Hist. Nat. 21: 250-260.

- 1922: Nonsymbiotic germination of orchid seeds. - Bot. Gaz. 73: 1-25.

Magrini, S., Barreca, D. \& Zucconi, L. 2019: A rapid double-staining technique to improve seed viability testing in terrestrial orchids. - Pl. Biosyst. 153(6): 877-882. https://doi.org/10.1080/11263504.2019.1587541.

—, De Carli, A., Onofri, S. \& Scoppola, A. 2011: A comparative study of the seed germination capabilities of Anacamptis palustris (Orchidaceae), a threatened terrestrial orchid, and other more common Anacamptis species, by asymbiotic culture in vitro. - Eur. J. Environ. Sci. 1: 71-79. https://doi.org/10.14712/23361964.2015.50

Malmgren, S. 1996: Orchid propagation: theory and practice. - Pp. 63-71 in Allen, C. (ed.) North American Native Terrestrial Orchid Conference Proceedings. - Germantown.

Oikonomidis, S., Koutsovoulou, K. \& Thanos, C. A. 2020: Germination of Neotinea maculata (Orchidaceae) in nutrient media and water agar. - Fl. Medit. 30: 394-399. https://doi.org/10.7320/FlMedit30.394

Pritchard, H. W. 1989: Modern methods in orchid conservation: The role of physiology, ecology and management. - Cambridge.

Rasmussen, H. N. 1995: Terrestrial orchids: from seed to mycotrophic plant. - Cambridge.

Zettler, L. W. \& Hofer, C. J. 1998: Propagation of the little club-spur orchid (Platanthera clavellata) by symbiotic seed germination and its ecological implications. - Environ. Exp. Bot. 39: 189195. https://doi.org/10.1016/S0098-8472\%2897\%2900019-1

Addresses of the authors:

Spyridon Oikonomidis ${ }^{1} \&$ Costas A. Thanos ${ }^{1}$,

${ }^{1}$ Department of Botany, Faculty of Biology, National and Kapodistrian University of Athens, 15784 Athens, Greece. E-mails: soikonomidis@biol.uoa.gr, cthanos@biol.uoa.grt 